\title{
Problems and cause analysis of the present situation of college students' entrepreneurial quality
}

\author{
Li Yue \\ *Education science key self-help topics in Jilin province (ZC13115) \\ Baicheng Normal College \\ School of Education Science 137000
}

\begin{abstract}
The entrepreneurship education with their quality as the content in our country has been carried out in recent twenty years, and high and low of college students' entrepreneurial quality can be illustrated as the most effective achievements of entrepreneurship education. This study has carried on the questionnaire survey of college students' entrepreneurship quality level in the current part of Jilin province, aimed at understanding the current problems of college students' entrepreneurial quality, to provide reference to better improve and perfect the entrepreneurship education in Jilin province.
\end{abstract}

Keywords: College students; Entrepreneurial quality; Problem; Reason

\section{INTRODUCTION}

Increasingly serious problem of university students' employment prompts higher education to make a new attempt and exploration in talent training mode, and cultivating students' entrepreneurial quality gets concern.In this background, in 1989 "education international seminar facing the 21 st century" held in Beijing had put forward the "education enterprise" concept, which has been translated into the "entrepreneurial education" later. Since then, entrepreneurship education in our country began to emerge and develop. The development in recent 20 years has made gratifying achievements, at the same time, the cultivation of college students' entrepreneurial quality has still some problems. Therefore, aiming at the problems existing in the entrepreneurship quality of college students, this paper has carried on the questionnaire survey and analysis of causes.

\section{Investigation object and tools}

The questionnaire this research adopts is "college students' entrepreneurial quality questionnaire" of the author. Through the statistical analysis, the questionnaire has good reliability and validity, in which $1 / 2$ reliability is measured 0.82 , retest reliability is 0.76 , and those can be used as the basis of college students' entrepreneurial quality survey. The questionnaire adopts the Likert five-point scale, including the pioneering consciousness, knowledge, the pioneering ability quality, psychological quality, four dimensions and 35 factors.

This research adopts the random sampling method to select parts profession students of parts of colleges and universities students in Jilin province, a total of 600 people as object of questionnaire survey, recycling 572effective questionnaire, and the effective rate was $95.3 \%$. Demographic characteristics distribution is 90 people of freshmen, accounting for $15.73 \%, 142$ people of sophomore, accounting for $24.83 \%$, 190 people of junior, accounting for $33.22 \%$, 150 people of senior, accounting for $26.22 \%$; Boys are 266 people, accounted for $46.50 \%$, girls are 306 people, $53.50 \%$; Children alone are 357 people, accounted for $62.41 \%$, the children not alone are 215 people, $37.59 \%$.

\section{Survey results}

(1) Pioneering consciousness is insufficient

The survey shows that college students' pioneering consciousness scores just achieve scale average score, 3.09 points, relatively low. It shows the entrepreneurship understanding of 
current college students is still not high, and the level of pioneering consciousness is lower. Especially female college students have scored only 2.68 points, and is significantly lower than that of male college students $3.53 \quad(\mathrm{P}<0.01)$; 2.79 points of not-only children are lower than 3.41 points of only children $(\mathrm{P}<0.05)$. Investigating its reason, on the one hand, it is influenced by Chinese traditional concepts, in which men have a lot of pressure to play to cause, feed their families and make a career; Women are the primary caregivers for husbands and children, and their work stress is relatively small. On the other hand, an important part of entrepreneurship is capital support, but the family economic pressure of only-child college students is larger than the one-child, so the possibility of funding is relatively small.

Seen from the subjects, $46.5 \%$ of the students think that the business is the best way to realize their own values and make an achievement, and $49 \%$ of the students think of a lot of difficulties appeared in the entrepreneurial process, and have the confidence; But only $32.5 \%$ of the students can be able to know what is suitable for their own entrepreneurial projects or entrepreneurial types, and really willing to start their own businesses, and who hope in the future to have their own enterprises are accounted for only $16.5 \%$ of investigation number. The data showed that most of the students held a positive attitude to entrepreneurship, and some students have certain interest and demand of entrepreneurship, then they can understand that entrepreneurship is the important way to realize their own values and make an achievement, but is just a beautiful wish, which stay on the speculative stage, students who really want to go to action, carry out and implement entrepreneurship were small. Overall, the college students' entrepreneurial enthusiasm is not high, and university students have ideal ambitious, tend to be more idealistic, and many students long for entrepreneurship which is not attainable, and stay only in imagination.

\section{(2) Business knowledge and experience are not enough}

College students' entrepreneurial knowledge scores are very low for 2.98, which have not reached scale average score. Among it, female college students scored only 2.71 points, and is significantly lower than that of male college students $3.17(\mathrm{P}<0.05)$; From the point of view of grade, freshman is 2.20 points, sophomore is 2.58 points, junior is 3.32 points, and senior is 3.82 points, then the freshman has the lowest score than other grades, and has very significant difference with the junior and senior $(\mathrm{P}<0.05)$. From the choice percentage of each topic, the proportion of students "think they have mastered the professional knowledge well, and can meet the need of entrepreneurship " was only $30.5 \%$, and $32.5 \%$ of students take negative view of it; Only $20 \%$ of students in life and study will know some social economic dynamic at home and abroad; $18 \%$ of students can focus on brainstorming, and Boston business show; The proportion on the mastery of the knowledge about operation and management is relatively low, and only $16 \%$ of students have a better understanding and cognition of knowledge and application to a company's operations; $15 \%$ of students know corresponding policies and laws and regulations about college students' entrepreneurial in some countries $15.5 \%$ of students can learn some marketing, human resource management, industrial and commercial tax, and financial management knowledge. On this several content, $56.4 \%$ of students chose "not in conformity with" and "completely not in conformity with". In the university entrepreneurship education curriculum system, entrepreneurial knowledge acquisition and the accumulation of experience are the main teaching purpose and content, however, the survey shows that the entrepreneurial knowledge and experience of current college students are still very few, which can not meet the needs of the real business.

\section{(3) Business ability is not strong}

According to the survey, college students' 
entrepreneurial ability score is 3.69 points. Among them, $27 \%$ of students don't know as a team leader, how to organize activities and deal with the relationship between members, and $37.5 \%$ of the students choose the middle entry; $24 \%$ of students are not good at dealing with people, and do not cooperate with people well, $36.5 \%$ of students choose the middle entry; $20 \%$ of students will irresolute and hesitant when they encounter problems, $20 \%$ of students choose the middle entry; $13.5 \%$ of students think their minds always lack of new ideas and points of view, $35.5 \%$ of the students choose the middle entry; $11 \%$ of students think they lack the ability to learn, and theory and practice are disjointed, $42 \%$ of students choose the middle entry; $19 \%$ of the students think they aren't good at discovering opportunity, and the combination ability of resource management is not strong, $41.5 \%$ of students choose the middle entry; $16 \%$ of students have poor ability to control and regulate mood, $31.5 \%$ of the students choose the middle entry; $16 \%$ of students think it difficult to discern the outside change, and in the face of emergencies cannot respond quickly, $44 \%$ of students choose the middle entry. These data show that in terms of entrepreneurial ability quality, the number of students who choose negative item is relatively high, but that of who choose the item in the middle is very high. On the one hand, this shows the current college students have not clear cognition to themselves, on the other hand, a majority of students are between can and can't, if there is a good quality training, we can believe that college students' career ability quality will be improved very well.

(4) Entrepreneurial psychological quality remains to be improved

In a questionnaire 13 questions are chose to correspond the 13 entrepreneurial psychological quality indicators respectively. Results show that the average score of college students' entrepreneurial psychological quality is 3.87 points, and score is higher compared with the pioneering consciousness and knowledge, which shows that the current college students already have a certain entrepreneurial psychological quality. However, specific indicators show that $20.1 \%$ of students think they lack of decisiveness and self-control, and volitional quality is weak, then $38 \%$ of students choose items in the middle. From comprehensive analysis of 13 indicators, it found that $12.2 \%$ of students think of themselves as the lower level of these 13 indicators, and psychological quality is not high, $34.7 \%$ of students choose items in the middle. Among the data results, the proportion of selecting the middle item is higher, which shows that many students still lack of the self active cognition and exercise, and the entrepreneurial psychological quality remains to be improved.

\section{Cause analysis}

\section{(1) Objective environmental factors}

\section{a. School factors}

The implement methods of current universities entrepreneurship education are realized mainly through setting some business related courses and organizing some entrepreneurial activities. This way, on the one hand, makes career education teaching lack organic connection with the professional learning of students, but is to pass on a kind of entrepreneurial techniques and skills, making entrepreneurship education and professional education disjointed, which is difficult to form a confluence of talent training, and became some extracurricular activities of students; On the other hand, the entrepreneurship education should have very strong systematic and pertinence, and the implementation way and the talent training of professional education are disjointed, which is hard to really develop the function of entrepreneurship education. Practice has proved that the entrepreneurial practice education lack of school-running concept level the education cannot fully build up the knowledge and ability structure entrepreneurial qualification training require, and doesn't really cultivate students' entrepreneurial quality. 


\section{b. Social factors}

The competition pressure of current society makes a lot of students hold attitude eager to reach towards entrepreneurship. Although the state has issued a series of policies to encourage people for self-employment and college entrepreneurship preferential measures, these policies also comes with some conditions at the same time, which makes college students who originally want to get some national policies for self-employment see their own not conform to the requirements and take a beating, lack of confidence, then interest and enthusiasm has a sudden drop in entrepreneurship. In addition, that the recognition degree of society to entrepreneurship behavior $\mathrm{s}$ and results of college students is not high is one of the influencing factors. In our traditional notion, only the talents who have poor ability and can't find a job can them to make entrepreneurship by themselves, and college students' entrepreneurship is often associated with the word "unemployment". Especially in the beginning, when there are no obvious achievements, once not getting the family and social recognition, entrepreneurs are likely to give up without suffering the pressure. As a result, many social factors affect the implementation of students' entrepreneurship, also reduce the students' consciousness of entrepreneurship, and affect the improvement of students' entrepreneurial quality to a great extent.

\section{c. Family factors}

The recognition and support degree of family to entrepreneurship directly affects students' entrepreneurial activities. On the one hand, influenced by traditional ideas, some parents don't understand the real meaning of entrepreneurship, and think their own children who do pioneering work have no face very much. The concept that the education background is supreme makes parents concern about the performance of their children only, care for very few for other aspects of the comprehensive quality, so the children understand only reading, but don't know how to live, to exchange, causing inadequate development of ability entrepreneurship much needed. On the other hand, although parents can understand entrepreneurship, but they think the possibility of the business success is very small, then don't let the child to try and support the children to do business, then this kind of negative cognition and the fear is passed to the children, causing insufficient business confidence of children, thus away from business, so entrepreneurship quality can't be promoted and developed naturally.

\section{(2) Subjective factors}

First, the self-awareness is not clear. Some students lack a correct and objective understanding about their personality traits, interests and abilities. They don't know their advantages what are, also don't know their own shortcomings. This lack of self-cognition makes them be in the following state, in which I do what others do, and finally their own ability quality, psychological quality still are not improved. Second, career goals and positioning are short. Many students go to college for the college. After entering the university, they have been in a relaxed state, and lack clear goals and career orientation, don't know what I can do, what to do. Third, the support of faith is inadequate. College students have been adult yet, but the economic source of university life is still given priority to the support of family, which makes them lack of taste of harsh realities. With no bitter, once meet with difficulties, students will fear, retreat, and lack of the belief for success. Entrepreneurial belief is the spiritual pillar of the college students in entrepreneurial activities, once support of faith lacks, it is difficult to have confidence to step over when entrepreneurs have a problem. Fourth, the business practice is short. The key of the entrepreneurship education is practice, if there is not practical support, it is difficult to form entrepreneurship ability of students. Due to the limited education resources in colleges and universities, the opportunities which are given 
for students to make entrepreneurship practice are limited. So students need to accumulate business practice experience through their own ways, the more rich experience is, the faster and the more productive the improvement of entrepreneurship quality is.

\section{CONCLUSIONS}

To sum up, the entrepreneurial quality level of current college students' is relatively low, especially the pioneering consciousness is insufficient, entrepreneurial knowledge especially lacks of performance, and this findings prompted the current entrepreneurship education to need to re-examine ourselves and reform reasonably, to make it provide more perfect service for the college students' entrepreneurial quality training.

\section{References}

[1] Peng Gang. Entrepreneurship education [M]. Nanjing: Jiangsu Education Press, 1995

[2] Chen Yan, Lei Yusheng, Cao Ranran. Investigation and thinking of college students' entrepreneurial quality[J]. Higher Education Exploration, 2006 (4)

[3] Ren Guoyou. Investigation and research of the college students' entrepreneurial quality[J]. Journal of China Institute of Labor Relations, 2006, 20 (5)

[4]Zeng Yuan. Present situation, problems and education countermeasures study of college students' entrepreneurial quality [J]. Journal of Jiangxi University of Science and Technology, 2011, 32 (4)

[5]Yu Guang, Wang Lihua. Present situation and countermeasure thought of Shanghai university students' entrepreneurship [J]. Journal of Ideological and Theoretical Education, 2013 (9) 